end point in the losartan group was reduced by $5.8 \%, 17.6 \%$ and $27.9 \%$ among patients with the II, ID, and DD genotypes, respectively $(P=0.215)$. The risk of end-stage renal disease alone was significantly reduced by use of losartan $(P=0.032)$, with reductions of $3.1 \%, 30.5 \%$, and $50.1 \%$ for the II, ID, and DD genotypes, respectively.

The authors conclude that patients with type 2 diabetic nephropathy who carry the $\mathrm{D}$ allele of the ACE gene have an unfavorable renal prognosis but derive greater benefit from losartan treatment than do those who carry only the I allele.

Original article Parving HH et al. (2008) ACE gene polymorphism and losartan treatment in type 2 diabetic patients with nephropathy. J Am Soc Nephrol 19: 771-779

\section{Clopidogrel 'ineffective' after percutaneous coronary intervention in patients with CKD}

Outcomes are particularly poor after percutaneous coronary intervention $(\mathrm{PCl})$ in patients with chronic kidney disease (CKD). Best et al. conducted a post hoc analysis of patients in the Clopidogrel for the Reduction of Events During Observation (CREDO) trial in order to assess the safety and efficacy of dual antiplatelet therapy with aspirin and clopidogrel following $\mathrm{PCl}$ in patients with CKD.

Participants were randomly assigned a loading dose of clopidogrel or placebo before undergoing PCl; all patients subsequently received clopidogrel and aspirin for 28 days, then aspirin and either clopidogrel or placebo-whichever they had originally been randomized to receivefor 1 year. In the 999 patients with normal renal function (estimated creatinine clearance $\geq 90 \mathrm{ml} / \mathrm{min} / 1.73 \mathrm{~m}^{2}$ ), clopidogrel was associated with fewer major cardiovascular adverse events than was placebo $(P=0.004$ at 28 days and $P=0.001$ at 1 year). There was, however, no significant relative risk reduction compared with placebo in the 1,003 patients with mild or moderate CKD (estimated creatinine clearance $<90 \mathrm{ml} / \mathrm{min} / 1.73 \mathrm{~m}^{2}$ ) at either 28 days or 1 year; in fact, there was a trend towards increased 1-year risk of a cardiovascular event in these individuals. There was no significant difference between the CKD and non-CKD groups in the incidence of clopidogrel-associated major or minor bleeding at 1 year.
Alterations in the metabolism and bioavailability of clopidogrel might explain the apparent lack of efficacy of this therapy after $\mathrm{PCl}$ in patients with CKD.

Original article Best PJ et al. (2008) The efficacy and safety of short- and long-term dual antiplatelet therapy in patients with mild or moderate chronic kidney disease: results from the Clopidogrel for the Reduction of Events During Observation (CREDO) trial. Am Heart J 155: 687-693

\section{Calcitriol has a modest antiproteinuric effect in IgA nephropathy}

Although angiotensin-converting-enzyme inhibitors and angiotensin-receptor blockers can slow deterioration of renal function in patients with IgA nephropathy, these drugs do not address the inflammatory component of the disease. Calcitriol (1,25-dihydroxyvitamin $\left.\mathrm{D}_{3}\right)$ has been reported to reduce progressive glomerular damage in subtotally nephrectomized rats. In an open-label, uncontrolled trial, Szeto et al. examined the antiproteinuric effect of calcitriol in 10 patients who had biopsy-proven IgA nephropathy and persistent proteinuria of more than $1 \mathrm{~g} /$ day (or urine protein to creatinine ratio $>1 \mathrm{~g} / \mathrm{g}$ ) despite use of an angiotensin-converting-enzyme inhibitor or angiotensin-receptor blocker for at least 6 months.

All patients received calcitriol $0.5 \mu \mathrm{g}$ twice weekly for up to 12 weeks and were followed up at weeks 2, 4, 6, 8 and 12. The dose was reduced if serum corrected calcium level exceeded $2.55 \mathrm{mmol} / \mathrm{l}(10.2 \mathrm{mg} / \mathrm{dl})$. Urinary protein to creatinine ratio declined from $1.98 \pm 0.74 \mathrm{~g} / \mathrm{g}$ at baseline to $1.48 \pm 0.81 \mathrm{~g} / \mathrm{g}$ at 6 weeks $(P<0.001)$, and the ratio remained lower than at baseline at 12 weeks $(P=0.004)$. No significant changes in blood pressure or renal function were noted during follow-up. Hypercalcemia was observed in one patient but resolved on reduction of the calcitriol dose to $0.25 \mu \mathrm{g}$ twice per week.

On the basis of these results, the authors conclude that further studies of the effect of calcitriol on persistent proteinuria are warranted. They estimate that a randomized controlled 1-year trial in 156 patients (78 per arm) would have sufficient statistical power to detect a significant effect.

Original article Szeto CC et al. (2008) Oral calcitriol for the treatment of persistent proteinuria in immunoglobulin A nephropathy: an uncontrolled trial. Am J Kidney Dis 51: 724-731 